\title{
Cellular Disorganization and Extensive Apoptosis in the Developing Heart of Mice that Lack Cardiac Muscle $\alpha$-Actin: Apparent Cause of Perinatal Death
}

\author{
ELTYEB ABDELWAHID, LAURI J. PELLINIEMI, JOHN C. SZUCSIK, JAMES L. LESSARD, AND \\ EERO JOKINEN \\ Department of Pediatrics [E.A.], MediCity Research Laboratories [E.A.] and Laboratory of Electron \\ Microscopy [L.J.P.], University of Turku, FIN-20520 Turku, Finland; Children's Hospital Medical Center \\ [J.C.S., J.L.L.], University of Cincinnati, Cincinnati, Ohio 45229-3039, U.S.A.; and Department of \\ Pediatrics [E.J.], University of Helsinki, FIN-00290 Helsinki, Finland
}

\begin{abstract}
Mice that lack cardiac muscle $\alpha$-actin die during the perinatal period. Approximately $56 \%$ of mice that are homozygous null $(-/-)$ for a functional cardiac $\alpha$-actin gene do not survive to term, and the remainder generally die within 2 wk of birth. We found that there were neither morphologic differences nor differences in the extent of apoptosis between the mutant and normal hearts on embryonic day (E) 12 and E14 of development. However, apoptosis was greater in the hearts of homozygous null mice on E17 and postnatal day 1 when compared with wild-type hearts. The antiapoptotic factor $\mathrm{Bcl}-\mathrm{x} / \mathrm{L}$ was localized in regions adjacent to where apoptosis was detected. The distribution patterns of the apoptosis triggering protein p53 were similar to those of apoptotic cells. The growth of the prenatal and postnatal hearts of the cardiac $\alpha$-actin-deficient mice was retarded, and the cytoplasmic filaments were disorganized. Although apoptotic
\end{abstract}

ABSTRACT

cells were observed in both the atria and ventricles in the hearts of the homozygous null animals, the frequency was greater in the ventricles than in the atria. Our results indicate that the functional and structural disturbances in the mice with a homozygous lack of cardiac $\alpha$-actin seem to be due to disorganized development of acto-myosin filaments in the affected cardiomyocytes. Other actin isoforms cannot compensate for the lack of cardiac $\alpha$-actin, and this seems to induce apoptosis in defective cardiac myocytes, which are not able to cope with the increased workload in the perinatal phase. (Pediatr Res 55: 197-204, 2004)
Abbreviation
TUNEL, terminal deoxynucleotidyl transferase-mediated dUTP nick-end labeling

The highly conserved actins are the major components of the thin filaments in the muscle sarcomere. In addition to two nonmuscle isoforms of actin, there are at least four tissuerestricted muscle isoforms: cardiac, skeletal, vascular, and enteric (1). Cardiac $\alpha$-actin is the striated muscle isoform that predominates in the adult mouse, pig, bovine, and human heart $(2,3)$. During cardiogenesis, vascular, skeletal, and cardiac actin genes are co-expressed in the chicken $(4,5)$, mouse $(6,7)$, rat (8), and human (9). However, in mature cardiac myocytes, only cardiac and skeletal actins are expressed, with cardiac actin representing the major $(\sim 80 \%)$ actin isoform that is

Received January 29, 2002; accepted November 22, 2002.

Correspondence: Eltyeb Abdelwahid, M.D., Ph.D., CBRC, Massachusetts General Hospital/Harvard Medical School, Building 149, 13th Street, Charlestown, MA 02129, U.S.A.; e-mail: eltyeb.abdelwahid@cbrc2.mgh.harvard.edu

Supported by Special State Fund (EVO) for Helsinki University Central Hospital and NIH Grant R01 HL57291 to J.L.L.

DOI: 10.1203/01.PDR.0000100900.56627.E1 present $(10,11)$. Cardiac $\alpha$-actin gene mutations have been suggested to affect sarcomere contraction and lead to familial hypertrophic and idiopathic dilated cardiomyopathy, compensatory hypertrophy of the heart, and heart failure (12-15). The mutations that give rise to such clinical manifestations are thought to cause defective cytoskeletal functioning and to provoke apoptosis (16).

Actin has been suggested to play a role in the regulation of cell growth and apoptosis (17), and evidence to this effect comes from a number of sources: 1) disruption of actinfilament integrity correlates to the induction of apoptosis in airway epithelia and has been suggested to be an early modulator of apoptotic commitment (18), and 2) changes in the DNA damage-induced apoptosis pathway have been observed in association with actin disruption (19), as has the activation of p53, a key regulator of apoptotic commitment (20).

Actin network may undergo disruption during morphologic modifications associated with apoptotic cell death (21), and 
actin is cleaved during constitutive apoptosis (22). In addition, down-regulation of actin genes may be involved in p53mediated apoptosis (23). It is clear, however, that mechanical stress that is a major cause of myocardial dysfunction evokes a variety of molecular and cellular events that can lead to important alterations in myocardial structure and function (or phenotype), such as hypertrophy and cardiomyocyte apoptosis (24). In addition, cardiomyocyte apoptosis has been shown to occur during myocardial diseases such as myocarditis and in end-stage cardiomyopathy (25).

Experimental disruption of the cardiac $\alpha$-actin gene in mice results in a lethal phenotype around the perinatal period (26). The present study was designed to determine the developmental changes in the embryonic, fetal, and postnatal heart of cardiac $\alpha$-actin null mice at the cellular level. We show that lack of a functional cardiac $\alpha$-actin gene results in defective myofilaments and increased apoptosis, which may lead to impaired function in the hearts of these mice and to subsequent death.

\section{METHODS}

Animals and surgical procedures for light microscopy. Hearts or whole embryos used in the analysis were collected on embryonic days 12 (E12), E14, and E17 and on the first postnatal day. To establish gestational age, timed matings were set up from 0900 to $1100 \mathrm{~h}$ between male and female mice that were heterozygous $(+/-)$ for the cardiac $\alpha$-actin defective allele. A vaginal plug at $1100 \mathrm{~h}$ was used as an indication of mating and set as day 0 of embryonic age for that litter. Pregnant female mice were placed in separate cages, and entire litters were collected at the appropriate time points. The pregnant female mice were killed by $\mathrm{CO}_{2}$ inhalation, and the embryos and/or fetuses were removed from the uterus and killed by decapitation. Whole embryos or surgically removed hearts were immediately placed in the freshly prepared $4 \%$ paraformaldehyde in PBS and fixed overnight at $4^{\circ} \mathrm{C}$, dehydrated, and embedded in paraffin. Serial sections, 5-7 $\mu \mathrm{m}$ in thickness, were cut and mounted onto silanized Superfrost slides and stored at $4^{\circ} \mathrm{C}$. For histology, sections were stained with hematoxylin and eosin. The study was approved by the Committee of the Faculty of Medicine, University of Turku, Finland.

Isolation and analysis of DNA. Isolation of genomic DNA from either tail biopsy or embryonic tissues and analysis was as previously described (26). For genotyping, DNA was digested with $P v u \mathrm{II}$, electrophoresed on $0.7 \%$ agarose gels and alkaline transferred to GeneScreen Plus (New England Nuclear, Boston, MA, U.S.A.). A $0.5-\mathrm{kb} S p h \mathrm{I}$ fragment from the cardiac $\alpha$-actin gene was radiolabeled with $\left[\alpha-{ }^{32} \mathrm{P}\right]$ dATP using a High Prime DNA Labeling Kit (Roche, Indianapolis, IN, U.S.A.). Hybridizations and washes were as previously described and exposed to PhosphorImager screens, which were analyzed on a Storm 860 or 820 PhosphorImager (Molecular Dynamics, Sunnyvale, CA, U.S.A.) (26).

Terminal deoxynucleotidyl transferase-mediated dUTP nick-end labeling analysis of apoptosis. Terminal deoxynucleotidyl transferase-mediated dUTP nick-end labeling
(TUNEL) analysis of apoptosis has been described in detail elsewhere (27). Briefly, the tissue sections were deparaffinized, hydrated, and then incubated with proteinase $\mathrm{K}(20 \mu \mathrm{g} / \mathrm{mL}$; Pharmacia, Uppsala, Sweden) for $15 \mathrm{~min}$ and assayed for apoptosis by TUNEL with alkaline phosphatase reaction (Boehringer, Mannheim, Germany). The color reaction was terminated by soaking the slides in $10 \mathrm{mM}$ of Tris and $1 \mathrm{mM}$ of EDTA ( $\mathrm{pH} \mathrm{8)}$, and the slides were then mounted with coverslips.

Immunohistochemistry. Immunohistochemistry was performed using the avidin-biotin-peroxidase complex method (28). Briefly, the sections were dewaxed and endogenous peroxidase activity was blocked with $\mathrm{H}_{2} \mathrm{O}_{2}$. Antigen retrieval was made by microwave treatment, and sections were incubated with nonimmune serum to block nonspecific binding and then incubated with the primary antibody: anti-Bcl-x/L $(\mathrm{S}-18$; Santa Cruz Biotechnology, Santa Cruz, CA, U.S.A.); anti-p53 (FL-393; Santa Cruz Biotechnology), and anti-atrial myosin light chain (provided by Dr. Steven W. Kubalak, Medical University of South Carolina, Charleston, SC, U.S.A.) (2931). After rinsing, sections were incubated with biotinylated secondary antibody and reacted with streptavidin-biotinperoxidase (Vector Laboratories, Burlingame, CA, U.S.A.). After rinsing, the reaction was visualized with diaminobenzidine, which labeled the positive nuclei or cells with a brown color. The reactions were lightly counterstained with hematoxylin, dehydrated, cleared, and mounted.

Conventional light and electron microscopy. The tissues were fixed with $5 \%$ glutaraldehyde and prepared according to standard procedures, as previously described (32). Sections for light microscopy were cut at $1 \mu \mathrm{m}$ and stained with toluidine blue. The thin sections $(70 \mathrm{~nm})$ were stained with $5 \%$ uranyl acetate and 5\% lead citrate in Ultrostainer (Leica, Vienna, Austria) and examined in a JEM-100SX (JEOL, Tokyo, Japan) transmission electron microscope. Paraformaldehyde and glutaraldehyde were purchased from Electron Microscopy Sciences (Fort Washington, PA, U.S.A.) and diluted appropriately on the day of use.

\section{RESULTS}

Early formation of the four-chambered embryonic heart on days E12 and E14. The cardiomyocytes had not yet differentiated to a histologically mature stage, and the endocardial cushion was dominated by nonmuscular cells. Ultrastructural examination confirmed the light microscopic observations that the development of the embryonic null $(-/-)$ hearts on E12 and E14 was normal but occasionally delayed. The endocardial cushion cells contained less atrial myosin light chain, used here as a cardiomyocyte marker (Fig. 1). Apoptosis was common in the cushion of all genotypes, i.e. normal $(+/+)$, heterozygous $(+/-)$, and null $(-/-)$ mice. In addition, considerable numbers of apoptotic cells in the limb during this period served as positive controls (data not shown). There were no major differences in the developing anatomical structures of the heart or the proportion of apoptotic cells among the different genotypes (Figs. 1 and 2). Apoptosis in the bulbar tissues was observed 

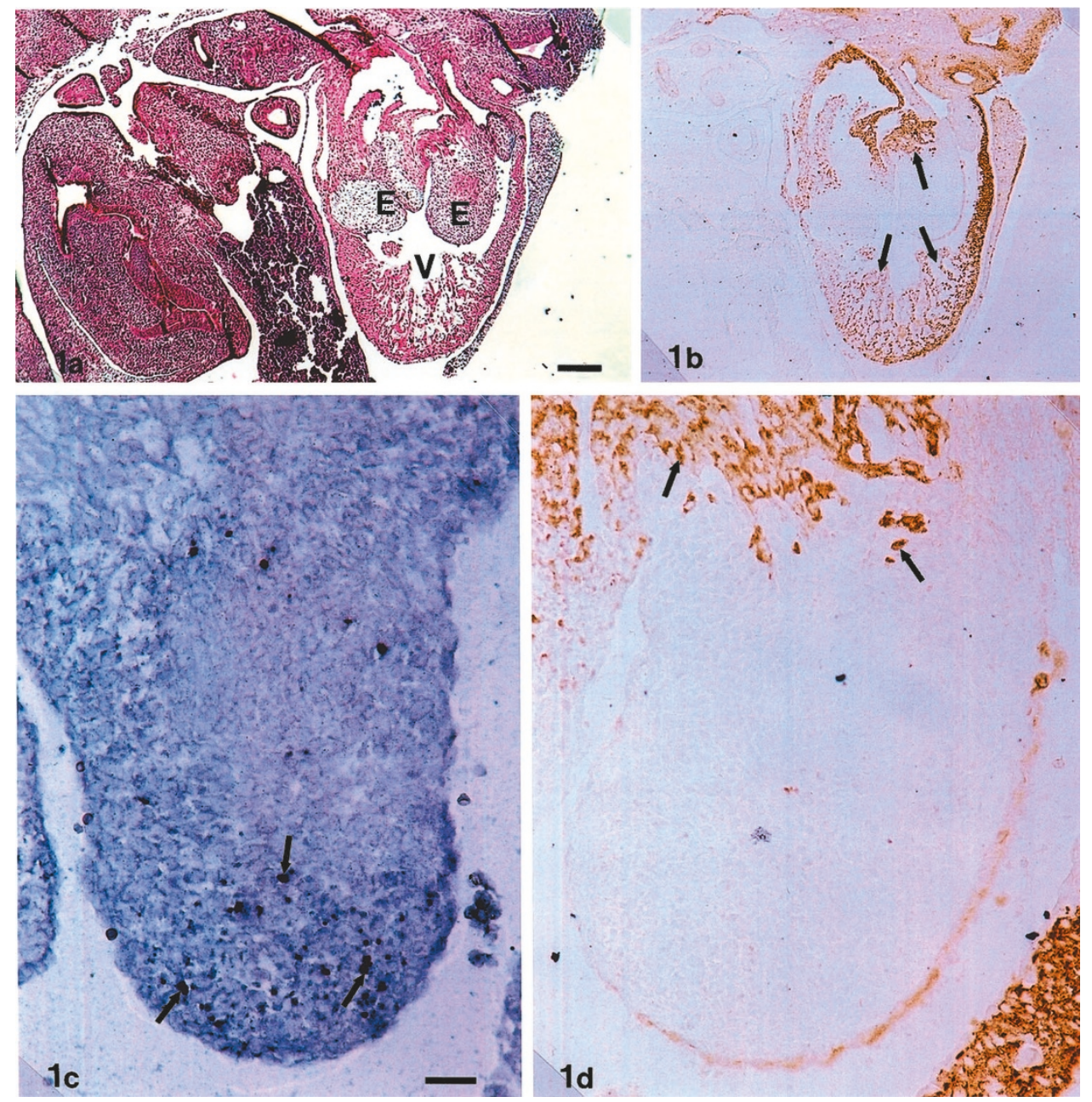

Figure 1. Serial sections of an embryonic heart lacking cardiac $\alpha$-actin (-/-) on E12. (a) Histologic development is normal. Hematoxylin-eosin stain. Scale bar $=100 \mu \mathrm{m}$. (b) Immunohistochemical localization (arrows) of atrial myosin light chain, a cardiomyocyte marker, is seen in the entire heart except in the developing endocardial cushion tissue (E in $a$ ). Scale bar $=100 \mu \mathrm{m}$. (c) Apoptotic cells (TUNEL analysis; arrows) are abundant in the endocardial cushion tissue before maturation of the muscular tissue. Scale bar $=20 \mu \mathrm{m}$. (d) High magnification of the reaction for the atrial myosin light chain (arrows) in the endocardial cushion. Scale bar $=20 \mu \mathrm{m}$. E, endocardial cushion; V, ventricle.

either in solitary cells or abundantly in regional cell clusters (Figs. 1 and 2).

Final formation of the heart on fetal day 17 and on the first postnatal day. Contrary to the normal embryonic hearts, at E17 the ventricular cavity was enlarged in the fetal and prenatal $-/-$ hearts, which was in accordance with apoptosis in the ventricles. The $-/-$ hearts were readily distinguishable from their $+/+$ and $+/-$ counterparts by their enlargement on E17 and postnatal day 1 . Histologic examination of the genetically manipulated hearts showed occasionally underdeveloped muscle tissue with cells detached sideways from each other (data not shown). The myocytes of $+/-$ hearts contained striated myofilaments similar to those of the $+/+$ animals. Both light and electron microscopy demonstrated abnormal structural and morphologic changes in the $-/-$ cardiomyocytes. These changes progressed between prenatal day 17 and postnatal day 1 and included nuclear changes accompanied by disorganization or loss of the myofibrils as well as other signs of degeneration. The plasma membrane, however, was often intact. Apoptotic cell death in these hearts was observed both by routine hematoxylin-eosin staining and by the TUNEL assay.
There was also mild, focal, single-myocyte degeneration. The number of apoptotic cardiomyocytes increased from E17 through the first postnatal day in the $-/-$ hearts in comparison with the $+/-$ and $+/+$ hearts. Apoptosis in the ventricular wall of the $-/-$ hearts was distributed in the compact wall and trabeculae as well as in the interventricular septum (Figs. 3 and 4). Apoptosis occurred in scattered cells throughout the heart at this stage. Although apoptotic cells were found in the atrial wall as well, apoptosis was less common than in the ventricular wall (Fig. 5). The antiapoptotic factor Bcl- $\mathrm{x} / \mathrm{L}$ was detected in $+/+$ (data not shown) and $-/-$ hearts. It was localized in the outer ventricular wall of the $-/-$ hearts (Fig. 4) and seemed to distribute in a complementary pattern in comparison with apoptosis. The localization of the apoptosis triggering protein p53 (Fig. 4) in the ventricular wall of cardiac $\alpha$-actin -/hearts revealed a pattern similar to that of apoptotic cells.

Ultrastructural observations showed the normal structure of the developing control hearts (Fig. 6). Electron microscopy revealed prominent nuclear chromatin condensation in the $-/-$ myocytes, confirming apoptosis. In degenerative muscular cells, there were occasionally normal organelles in the 

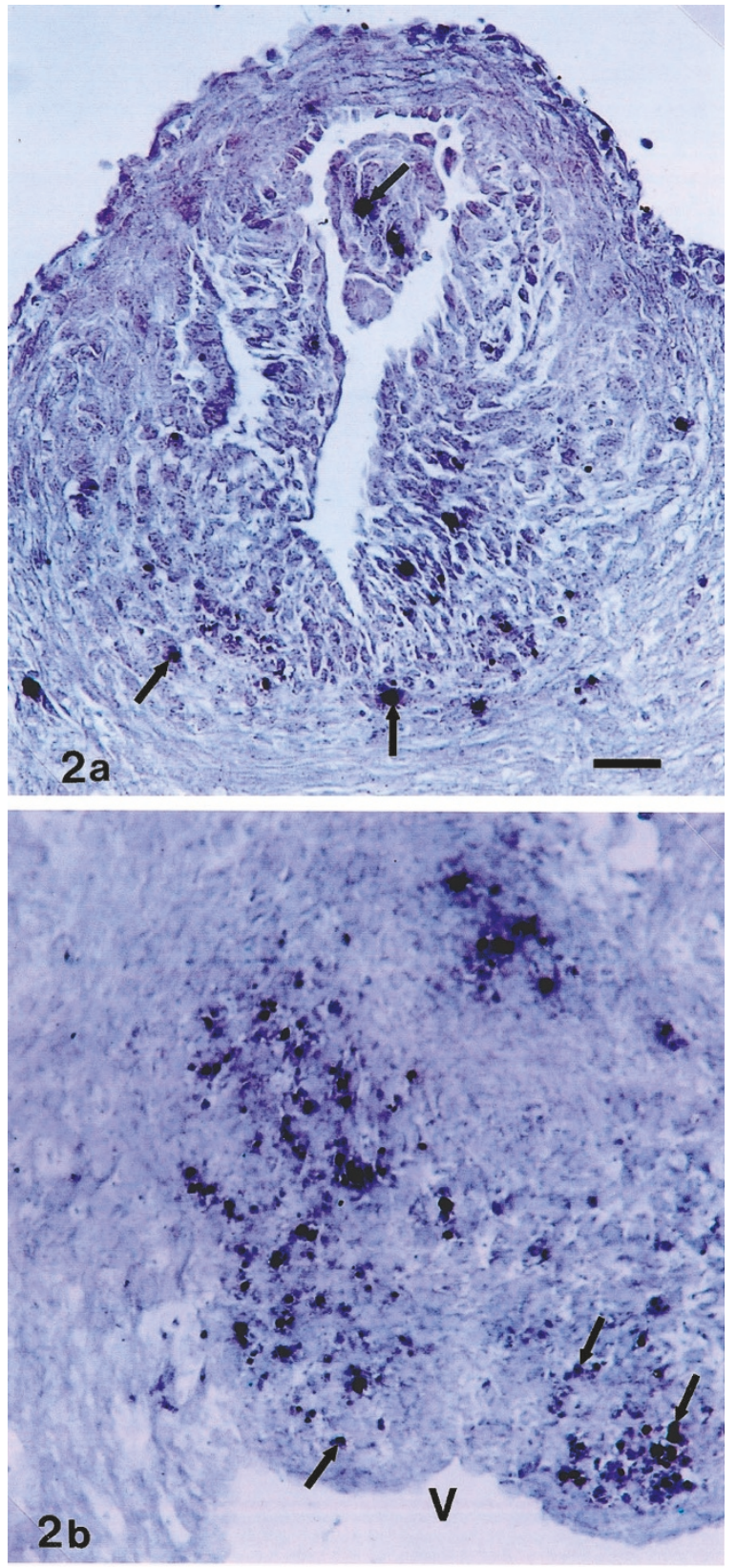

Figure 2. $(a, b)$ TUNEL analysis showing the abundance of apoptosis in the outflow tract of cardiac $\alpha$-actin $+/-$ heart mice on E14. Apoptotic cells (arrows) are seen in muscular (a, upper arrow) and bulbar parts (a, lower arrows, and $b$ ) of the outflow tract. V, ventricle. Scale bar $=20 \mu \mathrm{m}$.

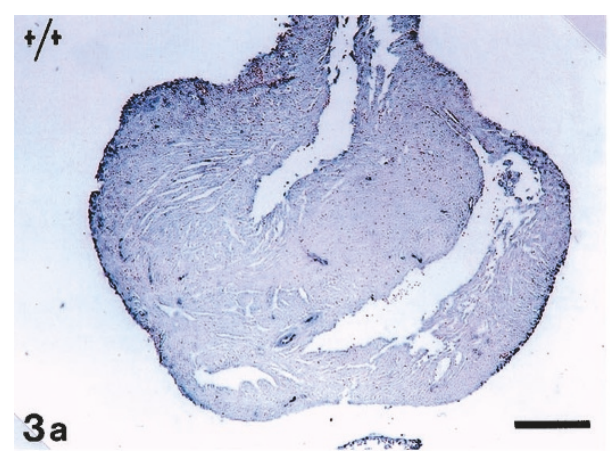

condensed cytoplasm. In the $-/-$ fetal and postnatal hearts, myofilaments apparently failed to organize into uniform bundles (Fig. 7). Their development was delayed and occasionally resembled younger, primitive, immature bundles. Myocyte degeneration was manifested as a loss of myofibrils, cytoplasmic condensation, condensed chromatin, and irregular size and shape of the myofilaments. These changes were accompanied by fragmentation of cellular material and disorganization of the myofibrils, increased intercellular space, accumulation of glycogen granules, degraded myofilaments, some fibrosis, and hypertrophic cardiomyocytes with connective tissue replacement (Figs. 7 and 8). Signs of delayed cardiac muscle development were not detected in wild-type littermates.

The active engulfment of the apoptotic bodies included occasional degenerating nuclei that did not reach an advanced apoptotic body stage (Fig. 9). Most of these phagocytosing cells contained many apoptotic fragments (Fig. 9). Despite the apoptotic features that appeared as blebbing of the cell membrane as well as condensed and fragmented nuclei, the apoptotic nuclear fragments were often not contained within a surrounding cell membrane, characteristic of the latest stages of apoptosis. Macrophages were identified by their cytoplasmic processes. Sometimes, infiltrating leukocytes, predominantly neutrophils, were visible. These leukocytes showed morphologic changes characteristic of apoptosis, with clumped chromatin and cytoplasmic shrinkage. This leukocyte infiltration was not accompanied by cardiomyocyte necrosis.

\section{DISCUSSION}

Apoptosis is a key process during organogenesis (33-35) that is involved in the genetically programmed structuring of the architecture of adult organs (36). In the heart, apoptosis is also a common mechanism of myocyte destruction during myocardial diseases (25).

Actin has been reported to play a central role in the control of cell growth, differentiation, and apoptosis (17), and, indeed, disruption of the actin-filament network has been associated with apoptosis $(18,19)$. Cardiac $\alpha$-actin gene mutations can lead to familial hypertrophic cardiomyopathy and idiopathic dilated cardiomyopathy by disturbing cardiac contraction and cause compensatory hypertrophy of the heart $(12,13,37)$. This indicates that actin loss may cause impaired contractility and also cell death by apoptosis and thus disturb the kinetics of the

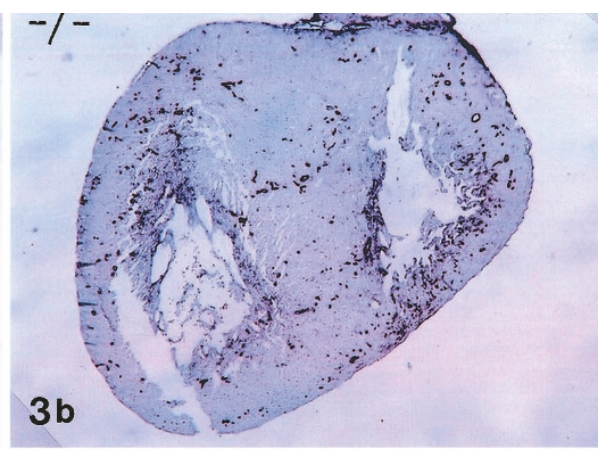

Figure 3. TUNEL analysis of apoptosis in cardiac $\alpha$-actin $+/+(a)$ and $-/-(b)$ hearts on the first postnatal day of mouse development. There are more apoptotic cells (arrows) in the $-/-$ than in the $+/+$ hearts. Scale bar $=200 \mu \mathrm{m}$. 

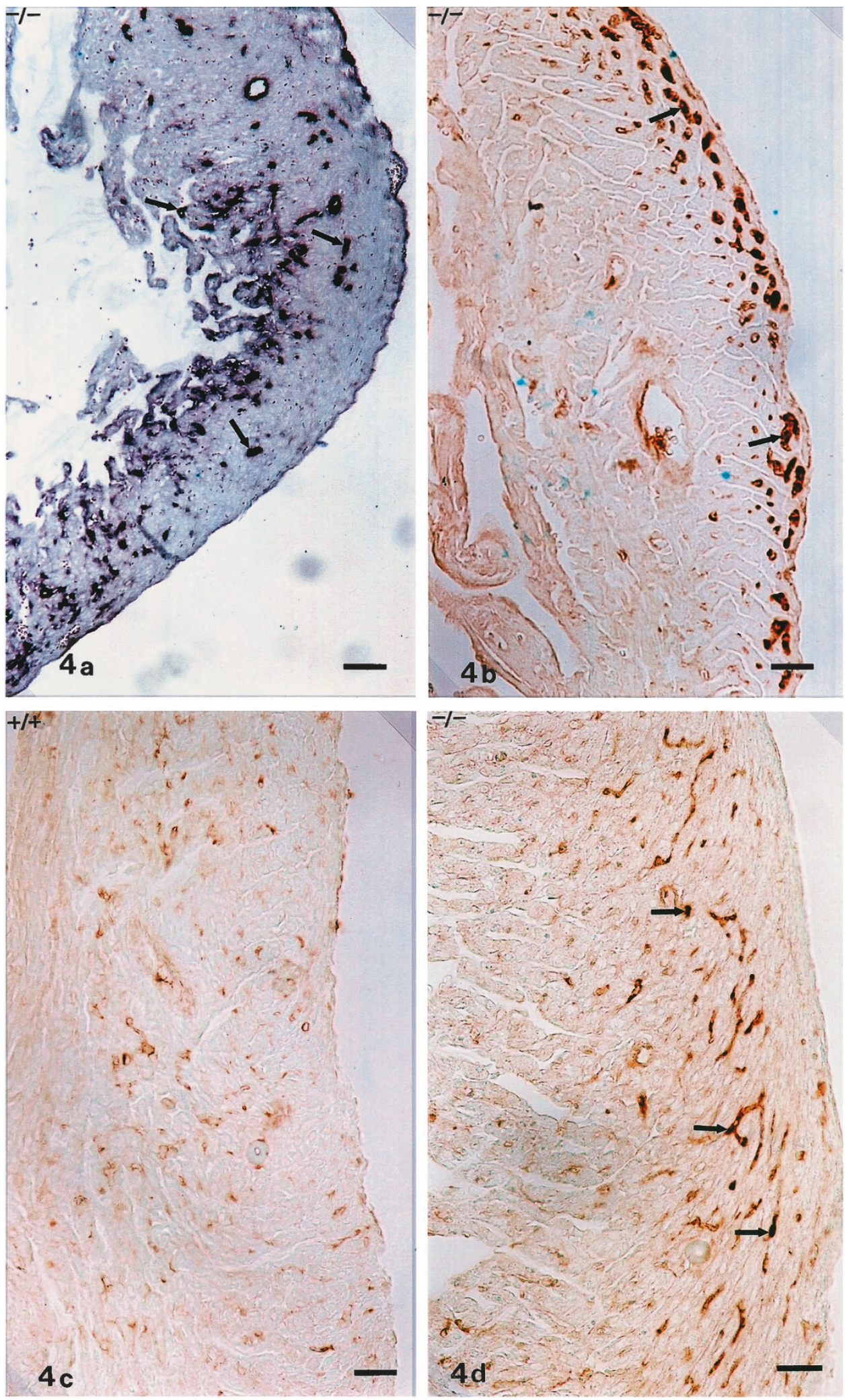

Figure 4. High magnification of the ventricular wall on postnatal day 1 of mouse heart development. (a) TUNEL reaction shows apoptotic cells (arrows) distributed in the mature compact wall and in the trabeculae (cardiac $\alpha$-actin $-/-$ heart). (b) Immunohistochemical reaction for the apoptosis inhibitory protein

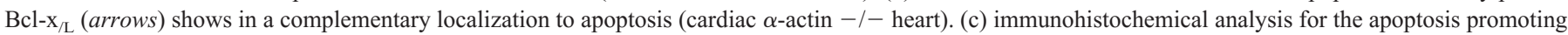
protein p53 (cardiac $\alpha$-actin $+/+$ heart). (d) Immunohistochemical reaction (arrows) for the apoptosis-promoting protein p53 (cardiac $\alpha$-actin $-/-$ heart). Scale bar $=20 \mu \mathrm{m}$. 

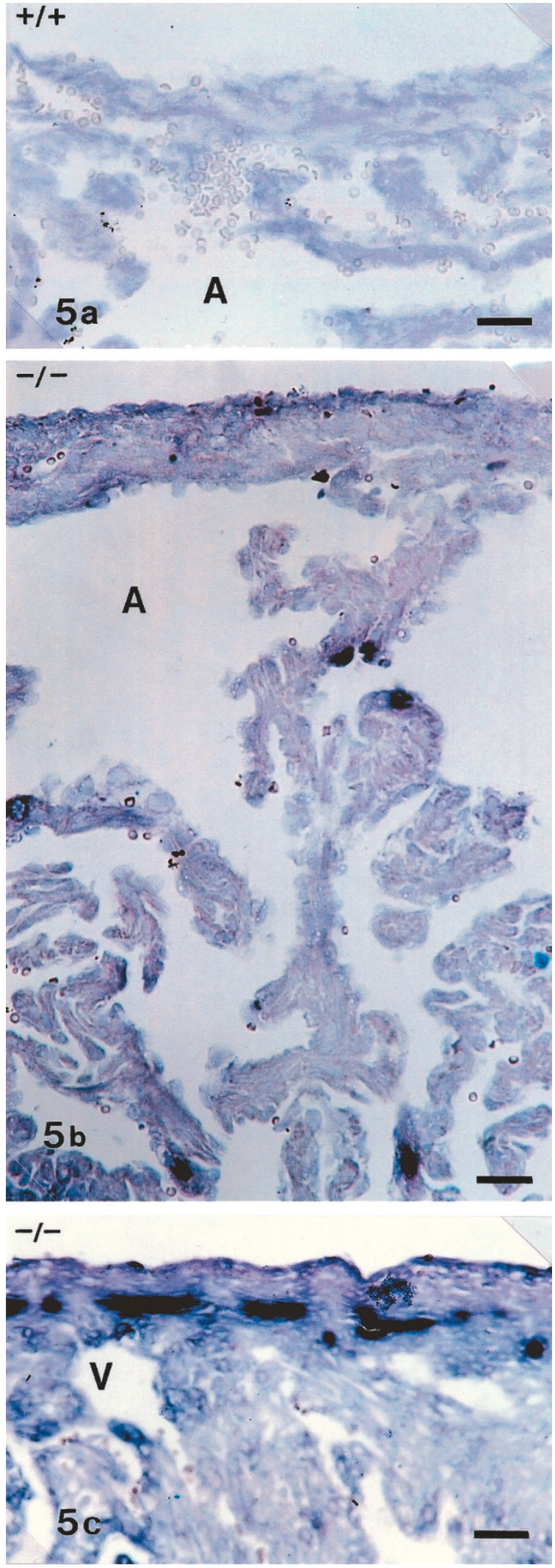

Figure 5. TUNEL analysis of apoptosis on the first postnatal day of mouse heart development. (a) No apoptotic cells are seen in the atrial wall of cardiac $\alpha$-actin $+/+$ heart. (b) Some apoptotic cells are seen in the atrial wall (cardiac $\alpha$-actin $-/-$ heart). (c) Apoptotic cells in the outer ventricular wall (cardiac $\alpha$-actin $-/-$ heart). There are more apoptotic cells in the outer ventricular myocardium in comparison with the outer wall of the atrium. A, atrium; V, ventricle. Scale bar $=20 \mu \mathrm{m}$

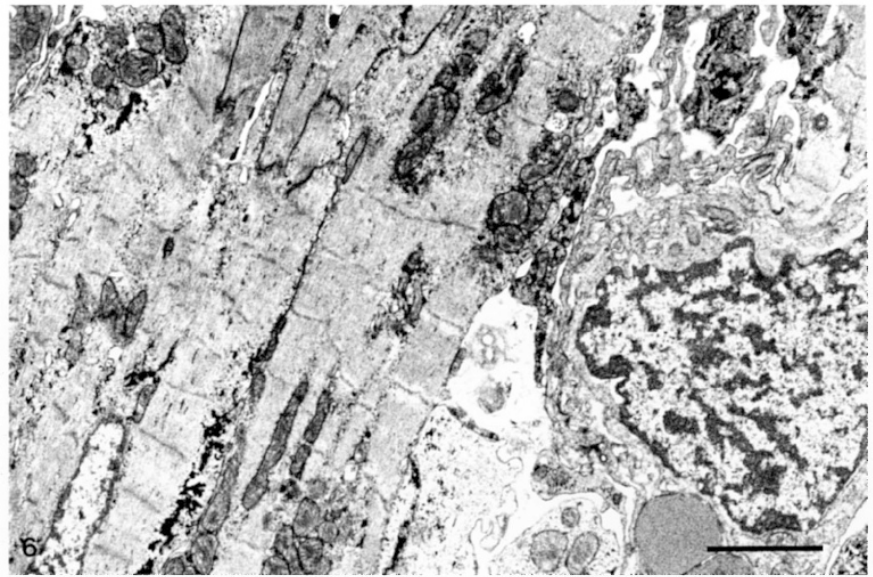

Figure 6. Electron micrograph of the cardiac $\alpha$-actin $+/+$ heart on the first day after birth. The specimen shows many, organized, well-aligned sarcomeres with normal myofibrillar organization. The cytoplasm of the myocytes contains normal organelles. Scale bar $=2 \mu \mathrm{m}$.

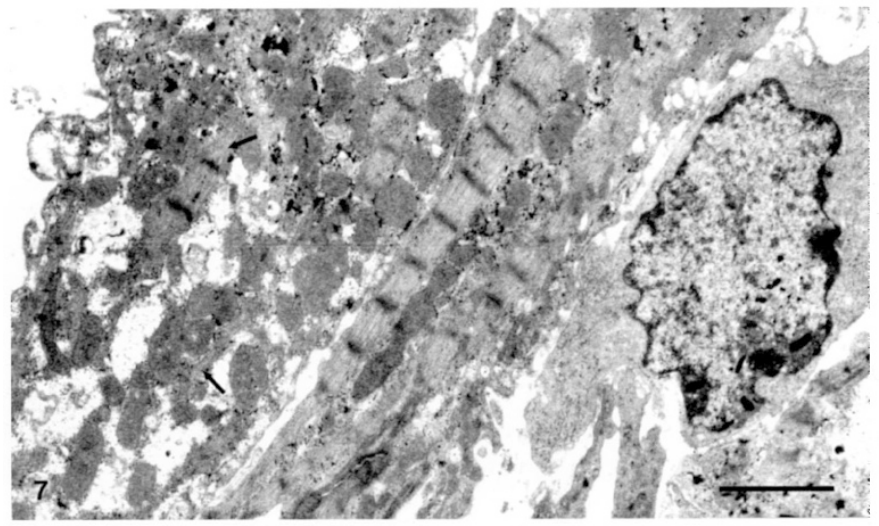

Figure 7. Electron micrograph of cardiac $\alpha$-actin $-/-$ heart on postnatal day 1. Disorganization of the myofilaments (arrows) indicates the abnormal structure of the myocardium. Scale bar $=2 \mu \mathrm{m}$.

whole heart (26). Cardiac failure is a major medical problem, which is characterized by cardiac dilation and pump dysfunction (38).

To investigate the role of cardiac $\alpha$-actin in cardiac apoptosis, we studied cardiac organogenesis in a cardiac $\alpha$-actin knock-out mouse. The experimental disruption of cardiac $\alpha$-actin gene in mice results in a lethal phenotype around the perinatal period (26). It is possible that the death of most of the $-/-$ mice is due to increased cardiomyocyte death. Because apoptotic cells are rapidly cleared by phagocytosis, we cannot ascertain whether apoptosis is extensive enough to be a cause of death of the animal. However, it is important to clarify the mechanisms needed to rescue cardiomyocytes from apoptosis.

Although both $+/+$ and cardiac $\alpha$-actin-deficient hearts in this study developed the full four chambers, most of the null mice did not survive, which suggests that apoptosis might be one mechanism leading to death (26). This is in accordance with our findings in the developing mouse that showed that the lack of a functional cardiac $\alpha$-actin gene leads to increased cardiomyocyte apoptosis on E17 and postnatal day 1 in null animals. Normal apoptotic activity was observed in the hearts of the mice with homozygous lack of cardiac $\alpha$-actin $-/-$ on 


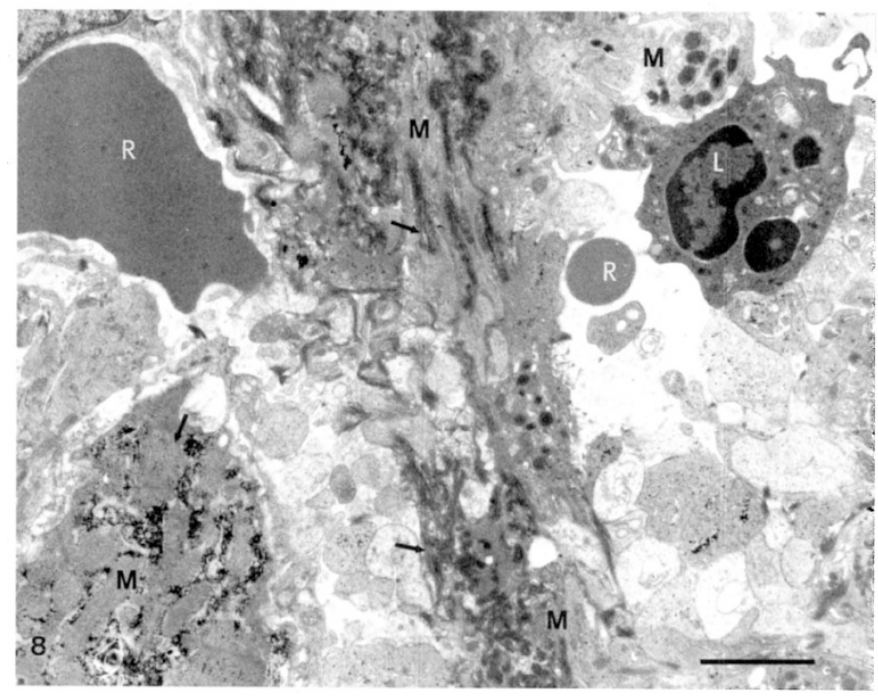

Figure 8. Electron micrograph of cardiac $\alpha$-actin $-/-$ heart on the first day after birth. There is advanced disorganization of myofilament (arrows). Note narrow fiber width, lack of integrity, and deviation from the normal parallel nature of thick and thin filaments (arrows). Severe degeneration of myofibrils is seen near the hypertrophied region. $\mathrm{L}$, leukocyte; $\mathrm{M}$, myofilament; $\mathrm{R}$, red blood cell. Scale bar $=2 \mu \mathrm{m}$.

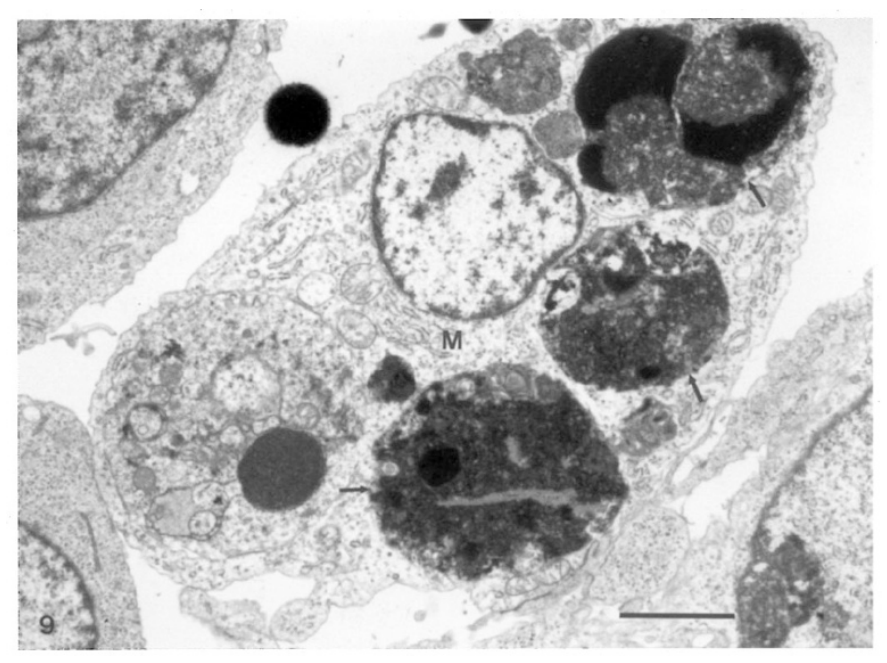

Figure 9. Electron micrograph of cardiac $\alpha$-actin $-/-$ heart on postnatal day 1 shows a macrophage (M) containing degenerating apoptotic bodies of phagocytosed cells (arrows). The apoptotic bodies contain remnants of pyknotic nuclei with highly condensed chromatin as well as disintegrated cytoplasmic organelles. Scale bar $=2 \mu \mathrm{m}$.

days 12 and 14 and was localized to developing cardiac cells as identified with a cardiomyocyte marker atrial myosin light chain (31). This indicates that the immature muscle cells have not, at this early stage, been considerably affected by cardiac $\alpha$-actin loss $(39,40)$. The trabeculae represent the most differentiated developing cardiac tissue and contain more muscle fibers than the compact ventricular wall (41). Increased apoptosis in the perinatal trabeculae of cardiac $\alpha$-actin mutations may also be due either to disruption of the muscular component or to direct contact and exposure to the pressure overload caused by the mechanical stress of the blood accumulation in the hypodynamic hearts (24). An alternative explanation could be the lack of sufficient pump activity in these hearts, which causes physiologic cardiac dysfunction and may be cardiomyopathy. Such physiologic effect maybe a factor that triggers apoptosis. Thus, occurrence of apoptosis seems to be related to the perinatal maturation of cardiac muscle fibers. There were more apoptotic cells in the ventricles than in the atria, which suggests that apoptosis is more critical for the structural stabilization of the ventricular myocardium.

Cardiac $\alpha$-actin gene may be required for cardiomyocyte survival by maintenance of the normal cardiac structure and functional dynamics during development as it is required for vital biologic events $(12,17)$. The present findings of delayed and disrupted cardiac differentiation and enlargement of hearts with extensive apoptosis suggest that actin is essential for the proper differentiation of the developing cardiomyocytes (11, 36 ). The lack of the cardiac $\alpha$-actin gene in the present animals may also evoke a signal to induce apoptosis and thus may cause the observed developmental defects.

The localization of apoptosis and the regulatory factors $\mathrm{Bcl}-\mathrm{x} / \mathrm{L}$ and $\mathrm{p} 53$ in the ventricular wall was consistent with the occurrence of apoptosis in these hearts. The disorganization of actin microfilaments may lead to the activation of p53 and thus promote apoptosis (20). This supports our finding of strong reaction for p53 in cardiac $\alpha$-actin gene $-/-$ hearts, which may be related to findings of down-regulation of actin genes in microfilament rearrangements during p53-mediated apoptosis (23). The role of actin in providing structural support and cell motility, as well as being a key component of cell membrane dynamics, might explain our observation of the absence of a cell membrane surrounds condensed and fragmented nuclear debris. This suggests that actin deficiency affects the formation of apoptotic bodies.

Mice that lack cardiac muscle $\alpha$-actin can be rescued to adulthood by expressing enteric actin under the control of the $\alpha$-myosin heavy chain gene promoter in the heart (26). Analysis of the "rescued" hearts may facilitate our understanding of the mechanisms that compensate for or exacerbate cardiac dysfunction. One possible explanation arises from our observation that apoptosis and $\mathrm{Bcl}-\mathrm{x} / \mathrm{L}$, the antiapoptotic protein, are expressed in a complementary pattern. Thus, stimulating expression of Bcl-x/L might reduce programmed myocyte loss, and this may ultimately rescue these animals.

\section{CONLUSION}

In conclusion, cardiac $\alpha$-actin-defective mice have enlarged hearts. We have shown that there is a defect in development and organization of the actomyosin complex, and apparently subsequent induction of apoptosis via impaired contractions and cell loss may cause morphologic and functional changes in these hearts. The development of the affected mutant cells is delayed, and apoptosis increases as development proceeds.

Acknowledgments. We thank Leena Salminen, Sirpa From, and Urpo Reunanen for excellent technical assistance with the electron microscopy. We thank Dr. Steven W. Kubalak, Medical University of South Carolina, for the generous gift of the atrial myosin light chain antibody. 


\section{REFERENCES}

1. Vandekerckhove J, Weber K 1979 The complete amino acid sequence of actins from bovine aorta, bovine heart, bovine fast skeletal muscle, and rabbit slow skeletal muscle. A protein-chemical analysis of muscle actin differentiation. Differentiation $14: 123-133$

2. Alonso S, Garner I, Vandekerckhove J, Buckingham M 1990 Genetic analysis of the interaction between cardiac and skeletal actin gene expression in striated muscle of the mouse. J Mol Biol 211:727-738

3. Vandekerckhove J, Bugaisky G, Buckingham M 1986 Simultaneous expression of skeletal muscle and heart actin proteins in various striated muscle tissues and cells. A quantitative determination of the two actin isoforms. J Biol Chem 261:1838-1843

4. Ordahl CP 1986 The skeletal and cardiac alpha-actin genes are coexpressed in early embryonic striated muscle. Dev Biol 117:488-492

5. Ruzicka DL, Schwartz RJ 1988 Sequential activation of alpha-actin genes during avian cardiogenesis: vascular smooth muscle alpha-actin gene transcripts mark the onset of cardiomyocyte differentiation. J Cell Biol 107:2575-2586

6. Sassoon DA, Garner I, Buckingham M 1988 Transcripts of alpha-cardiac and alpha-skeletal actins are early markers for myogenesis in the mouse embryo. Development 104:155-164

7. Lyons GE, Buckingham ME, Mannherz HG $1991 \alpha$-Actin proteins and gene transcripts are colocalized in embryonic mouse muscle. Development 111:451-454

8. McHugh KM, Crawford K, Lessard JL 1991 A comprehensive analysis of the developmental and tissue-specific expression of the isoactin multigene family in the rat. Dev Biol 148:442-458

9. Boheler KR, Carrier L, de la Bastie D, Allen PD, Komajda M, Mercadier JJ, Schwartz K 1991 Skeletal actin mRNA increases in the human heart during ontogenic development and is the major isoform of control and failing adult hearts. J Clin Invest 88:323-330

10. Herman IM 1993 Actin isoforms. Curr Opin Cell Biol 5:48-55

11. Lu MH, DiLullo C, Schultheiss T, Holtzer S, Murray JM, Choi J, Fischman DA, Holtzer H 1992 The vinculin/sarcomeric-alpha-actinin/alpha-actin nexus in cultured cardiac myocytes. J Cell Biol 117:1007-1022

12. Mogensen J, Klausen IC, Pedersen AK, Egeblad H, Bross P, Kruse TA, Gregersen N, Hansen PS, Baandrup U, Borglum AD 1999 Alpha-cardiac actin is a novel disease gene in familial hypertrophic cardiomyopathy. J Clin Invest 103:R39-R43

13. Bonne G, Carrier L, Richard P, Hainque B, Schwartz K 1998 Familial hypertrophic cardiomyopathy: from mutations to functional defects. Circ Res 83:580-593

14. Marian AJ, Roberts R 1998 Familial hypertrophic cardiomyopathy: a paradigm of the cardiac hypertrophic response to injury. Ann Med 3:24-32

15. Olson TM, Michels VV, Thibodeau SN, Tai YS, Keating MT 1998 Actin mutations in dilated cardiomyopathy, a heritable form of heart failure. Science 280:750-752

16. Rengan R, Ochs HD, Sweet LI, Keil ML, Gunning WT, Lachant NA, Boxer LA Omann GM 2000 Actin cytoskeletal function is spared, but apoptosis is increased, in WAS patient hematopoietic cells. Blood 95:1283-1292

17. Mashima T, Naito M, Noguchi K, Miller DK, Nicholson DW, Tsuruo T 1997 Actin cleavage by CPP-32/apopain during the development of apoptosis. Oncogene 14:1007-1012

18. White SR, Williams P, Wojcik KR, Sun S, Hiemstra PS, Rabe KF, Dorscheid DR 2001 Initiation of apoptosis by actin cytoskeletal derangement in human airway epithelial cells. Am J Respir Cell Mol Biol 24:282-294

19. Yamazaki Y, Dang Y, Shang X, Tsuruga M, Fujita Y, Tanaka H, Zhou D, Kawasaki $\mathrm{K}$, Oka S 2000 Acceleration of DNA damage-induced apoptosis in leukemia cells by interfering with actin system. Exp Hematol 28:1491
20. Rubtsova SN, Kondratov RV, Kopnin PB, Chumakov PM, Kopnin BP, Vasiliev JM 1998 Disruption of actin microfilaments by cytochalasin D leads to activation of $\mathrm{p} 53$. FEBS Lett 430:353-357

21. Suarez-Huerta N, Mosselmans R, Dumont JE, Robaye B 2000 Actin depolymerization and polymerization are required during apoptosis in endothelial cells. J Cell Physiol 184:239-245

22. Brown SB, Bailey K, Savill J 1997 Actin is cleaved during constitutive apoptosis. Biochem J 323:233-237

23. Guenal I, Risler Y, Mignotte B 1997 Down-regulation of actin genes precedes microfilament network disruption and actin cleavage during p53-mediated apoptosis. J Cell Sci 110:489-495

24. Colucci WS 1997 Molecular and cellular mechanisms of myocardial failure. Am J Cardiol 80:15L-25L

25. Narula J, Haider N, Virmani R, DiSalvo TG, Kolodgie FD, Hajjar RJ, Schmidt U, Semigran MJ, Dec W, Khaw BN 1996 Apoptosis in myocytes in end-stage heart failure. N Engl J Med 335:1182-1189

26. Kumar A, Crawford K, Close L, Madison M, Lorenz J, Doetschman T, Pawlowski S, Duffy J, Neumann J, Robbins J, Boivin GP, O’Toole BA, Lessard JL 1997 Rescue of cardiac alpha-actin-deficient mice by enteric smooth muscle gamma-actin. Proc Natl Acad Sci U S A 94:4406-4411

27. Billig H, Furuta I, Hsueh AJ 1994 Gonadotropin-releasing hormone directly induces apoptotic cell death in the rat ovary: biochemical and in situ detection of deoxyribonucleic acid fragmentation in granulosa cells. Endocrinology 134:245-252

28. Hsu SM, Raine L, Fanger H 1981 The use of antiavidin antibody and avidin-biotin peroxidase complex in immunoperoxidase technics. Am J Clin Pathol 75:816-821

29. Cahir-McFarland ED, Davidson DM, Schauer SL, Duong J, Kieff E 2000 NF-kappa $\mathrm{B}$ inhibition causes spontaneous apoptosis in Epstein-Barr virus-transformed lymphoblastoid cells. Proc Natl Acad Sci U S A 97:6055-6060

30. Webb BL, Jimenez E, Martin GS 2000 v-Src generates a p53-independent apoptotic signal. Mol Cell Biol 20:9271-9280

31. Kubalak SW, Miller-Hance WC, O’Brien TX, Dyson E, Chien KR 1994 Chamber specification of atrial myosin light chain-2 expression precedes septation during murine cardiogenesis. J Biol Chem 269:16961-16970

32. Fröjdman K, Paranko J, Virtanen I, Pelliniemi LJ 1992 Intermediate filaments and epithelial differentiation of male rat embryonic gonad. Differentiation 50:113-123

33. Abdelwahid E, Pelliniemi LJ, Jokinen E 2002 Cell death and differentiation in the development of the endocardial cushion of the embryonic heart. Microsc Res Tech 58:395-403

34. Poelmann RE, Molin D, Wisse LJ, Gittenberger-de Groot AC 2000 Apoptosis in cardiac development. Cell Tissue Res 301:43-52

35. van den Hoff MJ, van den Eijnde SM, Viragh S, Moorman AF 2000 Programmed cell death in the developing heart. Cardiovasc Res 45:603-620

36. Wyllie AH, Kerr JFR, Currie AR 1980 Cell death: the significance of apoptosis. Int Rev Cytol 68:251-306

37. Holmes KC, Popp D, Gebhard W, Kabsch W 1990 Atomic model of the actin filament. Nature 347:44-49

38. Abraham WT, Bristow MR 1997 Specialized centers for heart failure management. Circulation 96:2755-2757

39. Abdelwahid E, Eriksson M, Pelliniemi LJ, Jokinen E 2001 Heat shock proteins, HSP25 and HSP70, and apoptosis in developing endocardial cushion of the mouse heart. Histochem Cell Biol 15:95-104

40. Abdelwahid E, Rice D, Pelliniemi LJ, Jokinen E 2001 Overlapping and differential localization of Bmp-2, Bmp-4, Msx-2 and apoptosis in the endocardial cushion and adjacent tissues of the developing mouse heart. Cell Tissue Res 305:67-78

41. Abdelwahid E, Pelliniemi LJ, Niinikoski H, Simell O, Tuominen J, Rahkonen O, Jokinen E 1999 Apoptosis in the pattern formation of the ventricular wall during mouse heart organogenesis. Anat Rec 256:208-217 